\title{
Passion Play: Embracing New Scientific Perspectives for Improved Sport Psychology Consulting
}

\author{
Hagan Jnr John Elvis ${ }^{1,2^{*}}$, Schack Thomas ${ }^{1,2}$, Koester Dirk ${ }^{1,2}$ \\ ${ }^{1}$ Neurocognition and Action - Biomechanics"- Research Group, Faculty of Psychology and Sport Sciences, Bielefeld \\ University, 33501 Bielefeld, Germany
}

${ }^{2}$ Center of Excellence "Cognitive Interaction Technology" CITEC, Bielefeld University, Germany

Received: January 26, 2018; Accepted: January 30 2018; Published: January 302018

*Corresponding author: Hagan Jnr. John Elvis, Neurocognition and Action - Biomechanics- Research Group, Faculty of Psychology and Sport Sciences, Bielefeld University, 33501 Bielefeld, Germany; E-mail: elvis.hagan@ucc.edu.gh

\begin{abstract}
Despite recent advancements in sport sciences and technology across professional boundaries through research, education and training, it is remarkable that sport psychology consultants have not fully tapped into recent scientific and technological perspectives. This mini review gives brief insights on useful applications such as Virtual Reality (VR), Augmented Reality (AR), Eye tracking, Electroencephalography (EEG), and functional Magnetic Resonance Imaging (fMRI). These scientific methods could be employed to improve the cognitive functioning and athletes' performance, and serve as diagnostic and training tools for consultancy work.
\end{abstract}

Keywords: Neurocognition; Eye Tracking; Virtual Reality; Augmented Reality; Consulting;

\section{Introduction}

Over the past two decades, research and professional debates have raged on which approaches in sport psychology consulting would make the most significant contributions toward athletes' and other clients' life by creating a lasting positive behavior change [1,2]. Consequently, some researchers and sport psychology consultants have expressed reservations about the lack of scientific evidence-based interventions that underpin psychological processes in sport [3]. The quest for improving sport psychology consulting has proved daunting for researchers and consultants due to the wide array of issues confronting professional practice on roles and services (e.g., performance enhancement, psychological skills training, counseling delivery) they provide [4].

Despite the significant progress in recognizing the features and attributes necessary for improved consulting from athletes', teams and coaches' perspectives over the years, researchers and consultants are still searching for effective approaches that may enhance the advancement of scientific knowledge, skills and techniques needed to meet their clients' needs $[1,5]$. To date, contemporary intervention models have conventionally focused on two approaches: effectiveness of methods and interventions used in service delivery as well as the behavior and training experiences of athletes, and ethics of sport psychologists $[3,6,7,8]$. Though these cognitive-behavioral models have been significant in professional practice, there has been strong advocacy for alternate paradigms in the field [9].

The fundamental question is what constitutes acceptable "science" in sport psychology delivery? Current sport psychology delivery has been based on subjective judgments and assessments, and generally operates on intuitive basis instead of producing objective and actualized data from validated hypotheses, hypotheses supported by theorems, and theorems articulated from theories [3]. These valued processes provide objectification of knowledge, skills and attitudes that may shape service delivery through the outline of well-defined scientific procedures. Therefore, current practice is based on subjective experiences, intuition, and observations from inadequate samples which may not provide viable knowledge for effective interventions, calling for more dynamic approaches to service delivery. According to Strean \& Roberts, these procedures and methods lack critical examination and that professionals are not fully aware of the effectiveness of many procedures they use [3]. To move the sport psychology field forward, researchers and psychologists ought to empirically show the effectiveness of their interventions. By conscientiously assessing what they do rather than assume, findings and its' related interventions would be well established.

Despite recent advancements in sportsciences and technology across professional boundaries through research, education and training, it is surprising the sport psychology consultants have not fully tapped into recent scientific perspectives (e.g., Virtual Reality [VR], Augmented Reality [AR], Eye Tracking [ET], Mental Representations [MR], Electroencephalography [EEG], and functional Magnetic Resonance Imaging [fMRI] to promote the field [10]. For instance, VR and AR could be used to determine perceptual and/or auditory information as supplementary sources of feedback for motor learning. Data from athletes are 
accessed from multisensory components, audio-visual aids, actuators (types of motors used for moving or controlling mechanisms), and virtual actors. These measurements are recorded at different rates and synchronized to provide useful information on athletes' movements. Athletes' perspective and behavior within a VR/AR environment could then be related to

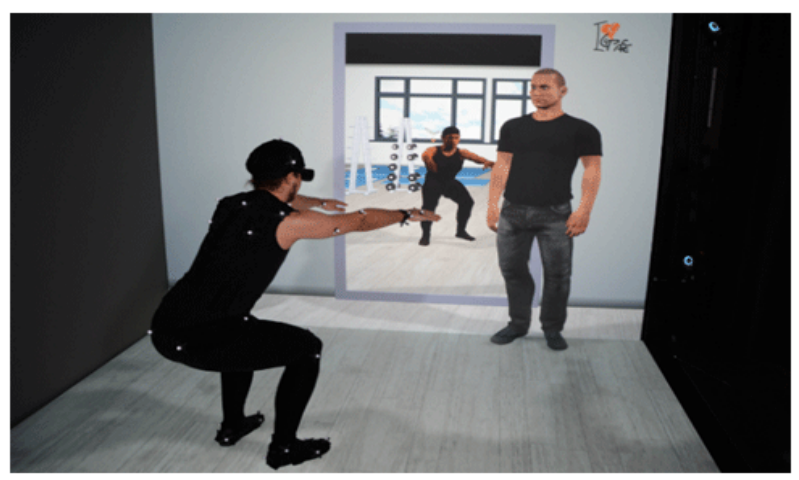

Figure 1: Virtual reality for sport exercises Photo: CITEC, Bielefeld University training.
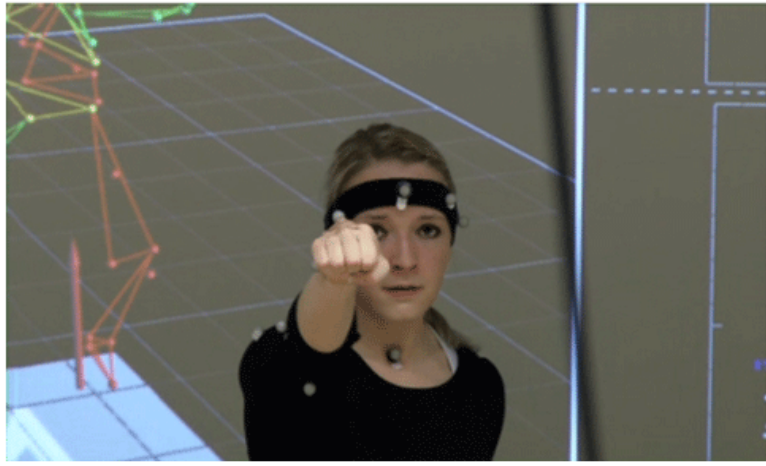

Figure 2: Virtual reality for karate. Photo: NCA, Bielefeld University

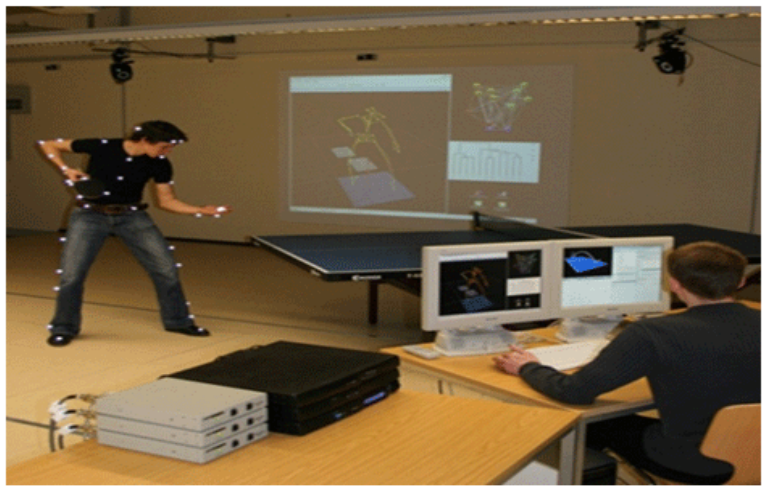

Figure 3: Augmented reality for table tennis. Photo: NCA, Bielefeld University

their perspective and behavior in real-life environments (Figure 1,2,3). Space precludes vivid descriptions for all the figures. For example, figure1 depicts a teacher-trainee scenario where a virtual coach supervises the acquisition of action sequences by verbally instructing participants and subsequently assesses changes in mental representation during skill learning in order to provide feedback. VR/AR facilitates better understanding of the perception-action loop for better sports analysis. Athletes and coaches could benefit from VR/AR settings via technologies to improve coach-athlete interaction that could complement technical preparations through competition-related training [11].

Scholarly evidence suggests that players' perspective and behavior within VR/AR environments could match closely to their behaviors in real-life environments. For example, Craig, Berton, Rao, Fernandez, and Bootsma used VR to examine curved free kicks in professional soccer players to determine whether a range of simulated free kicks would end up in the goal or not [12]. Findings revealed that players could imagine realistic free kicks by integrating information about their spins, and then used this information to accurately predict where the ball would end up after all other variables (e.g., ball speed) were controlled. Similarly, an immersive table tennis simulation study tagged as "V- Pong", used an integrated physics engine to manage three major features of simulation (ball movement, collision modelling, game strategy) to allow players interact with the ball in real time [13]. Ball movement (trajectory) improved the sensation of immersion and the extent to which players enjoyed the game, and game strategy modelled opponents' virtual behaviors.

Athletes may also benefit from the use of fully mobile, head-mounted eye tracking systems with in-built cameras that allow participants to move in an unrestrained working range on defined tasks in dynamic sport settings (i.e., field). Gaze behavior properties (fixation location, duration) are recorded and stored in the process for subsequent relational analyses. The spatial and functional association between eye movements and body movements or movement segmentations provide useful information for investigations on successful movement execution of how athletes' behave in unusual playing conditions [14]. Scientific investigations on gaze behavior characteristics have revealed that experts use fewer eye fixations of longer durations than non-experts across a wide range of sports on performance related tasks [15]. For example, Heinen, Jeraj, Vinken, and Velentzas found a relationship between gaze behavior and movement of a complex gymnastic skill (backward salto) performed as a dismount on uneven bars [16]. Thirteen experts were instructed to fix a light spot on a landing mat that varied systematically to each gymnast's landing distance during the downswing phase of salto dismount. Variations in hip angle at the top of the backswing, the duration of the downswing phase, hipangle prior to kick-through, and the landing distance as a function of different gaze locations on the landing mats were found. Other intervention studies have examined the usefulness of quiet eye (QE- final fixation) training in targeting skills such as shotgun shooting, soccer penalty shooting and golf putting $[17,18,19]$. Results revealed that QE underpins successful performance by differentiating both expertise (inter-individual) and proficiency (intra-individual), with experts and successful sporting attempts characterized by longer QE durations. 
Additionally, neurotechnologies (NT) such as EEG and fMRI are scientific methods that assess athletes' neurocognitive status through cognitive or neurophysiological measurements. Varied technological designs are used to monitor and improve brain function. These procedures provide vital information that help researchers and clinicians to visualize and stimulate the brain and memory on how varied characteristics of consciousness, thought, and higher order activities in the brain structures and motor memory operate.

For example, EEG biofeedback /neurofeedback can be used to train athletes by altering brainwaves through on board computer screen display (Figure 5). Two recent research investigations have assessed the patterns of cortical activity that influence successful golf putts, with findings forming empirical grounds for new neuro feedback interventions [20,21]. Patterns of EEG activity as per holed putts and missed putts were compared among expert and novice golfers. For instance, Cooke et al.'s findings suggested that expert golfers experienced a greater reduction in high EEG alpha power than novices, and that holed putts were characterized by less high-alpha power than missed putts at frontal and central sites (e.g., Fz, F3, F4, Cz) in two seconds before movement [21]. Similar results have been found in other self-paced voluntary movements investigations where EEG power was reduced in both hemispheres of the brain during bimanual tasks [22]. Therefore, EEG biofeedback serves as a powerful technique to help minimize or discard attention related problems, competitive anxiety and anger experienced by elite athletes. These goals could be achieved through perceptual-cognitive skills such as concentration, decision making, stress management and regulation of anxiety, and other emotional related problems through self-regulation [23].

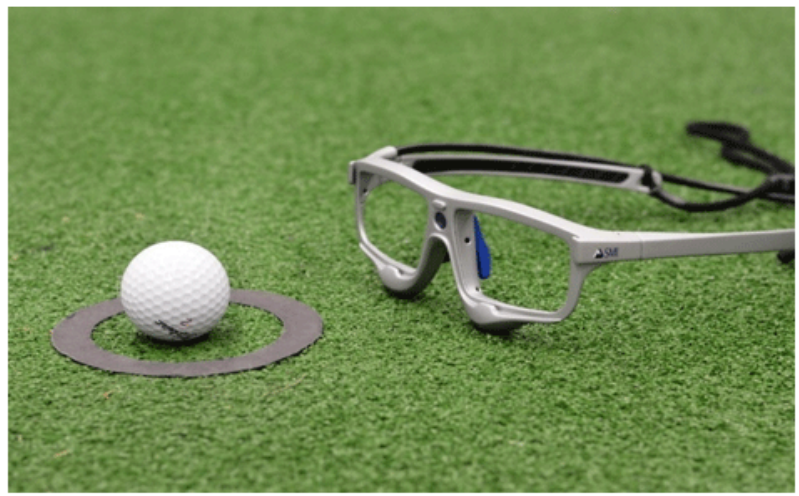

Figure 4:Eye tracking glasses. Photo: CITEC, Bielefeld University.

These aforementioned multidimensional scientific approaches have been successfully applied in variety of other competitive sports such as air pistol shooters, dance, golf, judo and tennis, rugby, handball, soccer and table tennis $[11,24,25,26,27,28]$. Similarly, mental representation structures of athletes of varied skill level have also been assessed using structural dimensional analysis of mental representation in refining technique related problems (SDA-M, for detailed description see [29]). Findings from these applications have been used to design suitable diagnostic procedures for appropriate psychological interventions. The framework for these interventions is derived from previous outlined databases that are synchronized to provide objective feedback. For example, integrated intervention routines may use AR and ET together with verbal scripts (task related instructions) and others like ideomotor training to correct technical errors in sports [30,31].

To deliver the most effective psychological interventions, sport psychology consults are encouraged to work harmoniously with other analogous personnel (e.g., cognitive, neuroscientists) within a specific sporting context. Moreover, identifying a specific problem through the formulation of hypothetical questions, and the significance behind the choice of questions, may determine possible outcomes. For instance, the use of fMRI may be beneficial in the laboratory or clinical settings because subjects must supinate when using the recording device and also for aiding rehabilitation after concussion or head injuries [32,33]. Finally, EEG can also be used to track motor learning experiences and performance enhancement (e.g., golf putting) [26,34].

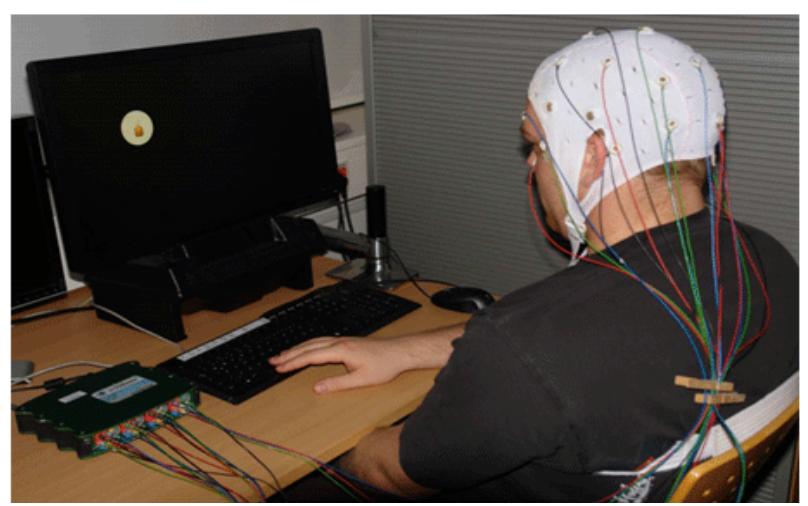

Figure 5:A wave guard EEG cap. Photo: CITEC, Bielefeld University.

\section{Conclusions}

Sport psychology professionals could apply, experiment, and/ or adapt these technological perspectives to make professional practice more visible and attractive to their clients (e.g., athletes, coaches, sport business or institutional investors) based on objective data (cf. $[23,35])$. The application of evidence-based tools in sport psychology consulting to generate individualized scientific information may help provide different conceptual frameworks for psychological skills interventions. Sport psychology consultants, athletes and coaches need to utilize varied scientific information that would enhance their awareness on valid procedures available to them. By appreciating these integrative roles in different situations and even individuals with whom they work, performance and long term behaviour changes in sports could be improved using more inclusive scientific perspectives. The challenge though may be how, when and where to comprehensively capture these useful scientific information for effective sport psychology consulting. 


\section{Acknowledgements}

This research article is supported by the Cluster of Excellence, Cognitive Interaction Technology (CITEC, [EXC 277]) at Bielefeld University and funded by the German Research Foundation (DFG).

\section{References}

1. Sharp L, Hodge K. Sport psychology consulting effectiveness: The sport psychology consultant's perspective. Journal of Applied Sport Psychology. 2011;23(3):360-376. doi: 10.1080/10413200.2011.583619.

2. SharpL,HodgeK.Sportpsychologyconsultingeffectiveness:Theathlete's perspective. International Journal of Sport and Exercise Psychology. 2014;12(2):91-105. doi: 10.1080/1612197X.2013.804285.

3. Strean WB, Roberts GC. Future directions in applied sport psychology research. The Sport Psychologist. 1992;6(1):55-65.

4. Singer RN, Anshel MH. An overview of interventions in sport. In J. Dosil (Ed.), The sport psychologists handbook: A guide for sport specific performance enhancement. Chichester: Wiley. 2006:63-88.

5. Tod D, Hutter RV, Eubank M. Professional Development for Sport Psychology Practice. Current Opinion in Psychology. 2017;16:134 -137. doi: 10.1016/j.copsyc.2017.05.007.

6. Vealey RS. Current status and prominent issues in sport psychology interventions. Medicine \& Science in Sports \& Exercise. 1994; 26:495502.

7. Partington J, Orlick T. An analysis of Olympic sport psychology consultants' best- ever consulting experiences. The Sport Psychologist. 1991;5(2):183-193.

8. Sachs ML. Professional ethics in sport psychology. In R.N. Singer, M. Murphey \& L.K. Tennant (Eds.), Handbook of research on sport psychology.New York: Macmillan. 1993:921-932.

9. Hardy L, Parfitt G. The development of a model for the provision of psychological support to a national squad. The Sport Psychologist. 1994;8(2):126-142.

10. Schack T, Bertollo M, Koester D, Maycock J, Essig K. Technological advancements in sport psychology. In A. Papaioannou \& D. Hackfort (Eds.), Routledge Companion to Sport and Exercise Psychology: Global Perspectives and Fundamental Concepts. London: Routledge. 2014:953-966.

11. Bideau B, Kulpa R, Vignais N, Brault S, Multon F, Craig C. Using virtual reality to analyze sports performance. IEEE Computer Graphics and Applications. 2010;30(2):14-21.

12. Craig CM, Berton E, Rao G, Fernandez L, Bootsma RJ. Judging where a ball will go: The case of curved free kicks in football. Naturwissenschaften. 2006;93(2):97-101. doi:10.1007/s00114-005-0071-0

13. Brunett G, Rusdorf S, Lorenz, M. V-Pong: An immersive table tennis simulation. IEEE Computer Graphics and Applications. 2006;26(4):1013. doi:10.1109/MCG.2006.92

14. Essig K, Prinzhorn D, Maycock J, Ritter H, Schack T. Automatic analysis of 3D gaze coordinates on scene objects using data from eye-tracking and motion-tracking systems. In Eye Tracking Research \& Applications (ETRA 2012). Santa Barbara, California, USA. 2012.

15. Nieuwenhuys A, Pijpers JR, Oudejans RRD, Bakker FC. The influence of anxiety on visual attention in climbing. Journal of Sport \& Exercise Psychology. 2008;30(2):171-185. doi:10.1123/jsep.30.2.171

16. Heinen T, Jeraj D, Vinken PM, Velentzas K. Land where you look? Functional relationships between the gaze and movement behavior in a backward salto. Biology of Sports. 2012;29(3):177-183. doi:10.5604/20831862.1003276

17. Causer J, Holmes PS, Williams AM. Quiet eye training in a visuomotor control task. Medicine and Science in Sports and Exercise. 2011;43(6):1042-1049. doi: 10.1249/MSS.0b013e3182035de6

18. Wood G, Wilson MR. Quiet-eye training for soccer penalty kicks. Cognitive Processing.2011;12(3):257-266. doi: 10.1007/s10339011-0393-0

19. Vine SJ, Moore LJ, Wilson MR. Quiet eye training facilitates competitive putting performance in elite golfers. Frontiers in Psychology. 2011;2(8);1-9. doi:10.3389/fpsyg.2011.00008

20. Babiloni C, Del Percio C, Iacoboni M, Infarinato F, Lizio R, Marzano N. et al. Golf putt outcomes are predicted by sensorimotor cerebral EEG rhythms. Journal of Physiology. 2008;586(1):131-139. doi:10.1113/ jphysiol.2007.141630

21. Cooke A, Kavussanu M, Gallicchio G, Willoughby A, McIntyre D, Ring C. Preparation for action: Psychophysiological activity preceding a motor skill as a function of expertise, performance outcome, and psychological pressure. Psychophysiology.2014;51(4):374-384. doi:10.1111/psyp.12182

22. Leocani L, Toro C, Manganotti P, Zhuang P, Hallett M. Eventrelated coherence and event-related desynchronization/ synchronization in the $10 \mathrm{~Hz}$ and $20 \mathrm{~Hz}$ EEG during self-paced movements. Electroencephalography and Clinical Neurophysiology. 1997;104(3):199-206.

23. Schack T, Hackfort D. An action theory approach to applied sport psychology. In G. Tenenbaum \& R. C. Eklund (Eds.), Handbook of Sport Psychology (3rd ed.) NJ: Wiley. 2007:332-351.

24. Cheng MY, Wang KP, Hung CL, Tu YL, Huang CJ, Koester D, Schack T. et al. Higher power of sensorimotor rhythm is associated with better performance in skilled air-pistol shooters. Psychology of Sport and Exercise. 2017;32:47-53. doi:10.1016/j.psychsport.2017.05.007

25. Bläsing B, Puttke M, Schack, T. (Eds.) Neurocognition of dance. London: Psychology Press. 2010.

26.Cheng MY, Huang CJ, Chang YK, Koester D, Schack T, Hung TM. Sensorimotor rhythm neurofeedback enhances golf putting performance. Journal of Sport \& Exercise Psychology. 2015;37(6):626636. doi:10.1123/jsep.2015-0166.

27. Weigelt M, Ahlmeyer T, Lex H, Schack T. The cognitive representation of a throwing technique in judo experts - Technological ways for individual skill diagnostics in high-performance sports. Psychology of Sport and Exercise. 2011;12(3):231-235. 
28. Schack T, Mechsner F. Representation of motor skills in human longterm memory. Neuroscience Letters. 2006;391(3):77-81.

29. Schack T. Measuring mental representations. In G. Tenenbaum and B. Eklund (Eds.), Handbook of Measurement in Sport. Champaign, IL: Human Kinetics; 2012. . 203-214.

30. Kunde W, Koch I, Hoffmann J. Anticipated action effects affect the selection, initiation, and execution of actions. Quarterly Journal of Experimental Psychology. 2004;57(1):87-106.

31. Schack T, Bockemuehl T, Schütz C, Ritter H. Augmented Reality im Techniktraining. BISp-Jahrbuch 2007/8. Bonn: BGoMedia GmbH \& Co. KG. 2008:235-240.
32. Tashiro M, Itoh M, Fujimoto T, Masud MM, Watanuki S, Yanai K. Application of positron emission tomography to neuroimaging in sports sciences. Methods. 2008;45(4):300-306.

33. Pulsipher DT, Campbell RA, Thoma RJ, King JH. A critical review of neuroimaging applications in sports concussion. Current Sports Medicine Reports. 2011;10(1):14-20.

34. Pitto L, Novakovic V, Basteris A, Sanguineti V. Neural correlated of motor learning and performance in a virtual ball putting task. IEEE International Conference of Rehabilitation Robot; Zurich, Switzerland. 2011:2011.

35. Schack T, Bar-Eli M. Psychological factors in technical preparation. In B. Blumenstein, R. Lidor, \& G. Tenenbaum (Eds.), Psychology of sport training. Oxford: Meyer \& Meyer Sport. 2007;62-103. 